\title{
A Kinetic Approach to the Alkylating Potential of Carcinogenic Lactones
}

\author{
José A. Manso, M. Teresa Pérez-Prior, M. del Pilar García-Santos, \\ Emilio Calle, and Julio Casado* \\ Departamento de Química física, Universidad de Salamanca, E-37008 Salamanca, Spain
}

Received February 7, 2005

\begin{abstract}
The alkylating potential of $\beta$-propiolactone (BPL), $\beta$-butyrolactone (BBL), $\gamma$-butyrolactone, and $\delta$-valerolactone, which can be formed by the in vivo nitrosation of primary amino acids, was investigated kinetically. The nucleophile NBP, 4-( $p$-nitrobenzyl)pyridine, a trap for alkylating agents, was used as an alkylation substrate. The alkylation reactions were performed under mimicked cellular conditions at neutral $\mathrm{pH}$ in water/dioxane solvent mixtures. To gain insight into the effect of the hydrolysis of lactones on their alkylating efficiency, alkylation and competing hydrolysis were studied in parallel. Conclusions were drawn as follows: (i) $\gamma$-Butyrolactone and $\delta$-valerolactone afford neither appreciable NBP alkylation nor hydrolysis reactions; (ii) the alkylating potential of BPL is 10-fold higher than that of BBL, the reactivity of both being essentially enthalpy-controlled; (iii) a correlation was found between the alkylating potential of lactones and their carcinogenicity; (iv) the hydrolysis of lactones is not sufficiently effective to prevent alkylation; (v) the efficiency of alkylation, expressed as the alkylation rate/ hydrolysis rate ratio, decreases strongly with increasing amounts of dioxane in the reaction media; (vi) the absorption coefficients of the NBP-lactone adducts are as follows: $\epsilon_{\mathrm{NBP}-\mathrm{BPL}}=$ $5101 \pm 111 \mathrm{M}^{-1} \mathrm{~cm}^{-1}(\lambda=584 \mathrm{~nm})$ and $\epsilon_{\mathrm{NBP}-\mathrm{BBL}}=462 \pm 19 \mathrm{M}^{-1} \mathrm{~cm}^{-1}(\lambda=586 \mathrm{~nm})$, the pronounced difference between these values being rationalized in terms of the adducts' structure; and (vii) linear correlations exist between the adducts' absorption coefficients and the water/dioxane ratio in the reaction media.
\end{abstract}

\section{Introduction}

In previous work (1-3), it was shown that the species resulting from the nitrosation of primary amino acids are the corresponding lactones. Some lactones give alkylating reactions with any of a number of nucleophilic sites in tissues, and because alkylating agents are considered archetypal carcinogens (4), considerable efforts have been devoted to addressing the chemical carcinogenesis caused by these species (5).

While carcinogenesis elicited by lactones has long been known, to our knowledge, the alkylating potential of these species has not been investigated in quantitative chemical terms and even less so when concurrent with other reaction pathways, such as hydrolysis, which should diminish the efficiency of lactones as alkylating agents.

In the present work, we performed a kinetic study of the alkylating potential of $\beta$-propiolactone (BPL), $\beta$-butyrolactone (BBL), $\gamma$-butyrolactone (GBL), and $\delta$-valerolactone (DVL) (Figure 1).

The nucleophile NBP, 4-( $p$-nitrobenzyl)pyridine, a trap for alkylating agents $(6)$ with nucleophilic characteristics similar to DNA bases (7), was used as the alkylation substrate. To gain quantitative knowledge about the effect of the hydrolysis of lactones on their alkylating capacity, both competing reactions-hydrolysis and alkylation-were studied in parallel. Previous work on

* To whom correspondence should be addressed. Tel: +34 923 294486. Fax: +34 923 294574. E-mail: jucali@usal.es.
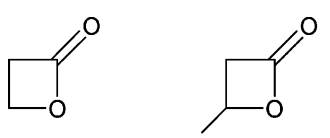

BPL

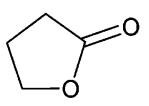

GBL

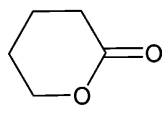

DVL

Figure 1. Chemical structures of the studied lactones.

the hydrolysis of lactones had been carried out in neutral and acid media (8).

Hydrolysis and alkylation reactions were investigated under mimicked cellular conditions $(7,9)$ at neutral $\mathrm{pH}$ in water/dioxane solvent mixtures to accommodate NBP. The reactions were performed at various temperatures between 25 and $35{ }^{\circ} \mathrm{C}$.

\section{Experimental Procedures}

Caution: Because BPL and BBL are possibly carcinogenic for humans $(4,5)$, they should be handled carefully.

The hydrolysis of lactones (performed in 7:3 water/dioxane media; see below) was monitored by titration of the resulting hydroxy acids (Scheme 1). The concentration of hydroxy acid was determined by titration with $\mathrm{NaOH}$, this latter being titrated with potassium hydrogen phthalate. In the titration procedure, $1 \mathrm{~mL}$ aliquots of the reacting mixture (lactone and unbuffered $\mathrm{CO}_{2}$-free water) were removed from time to time, added to $9 \mathrm{~mL}$ of ice water, and titrated immediately to a bromthymol blue end point [the hydroxy acid $\mathrm{p} K_{\mathrm{a}}$ values are in the 4.5-4.7 range (10)]. Detailed reaction conditions are given in the figure and table legends.

To monitor the alkylation reactions, $2.4 \mathrm{~mL}$ aliquots of the alkylation mixture (lactone $+\mathrm{NBP}$ ) were removed at different times and added to a cuvette containing $0.6 \mathrm{~mL}$ of $99 \%$ 
Scheme 1. Hydrolysis of BPL and BBL

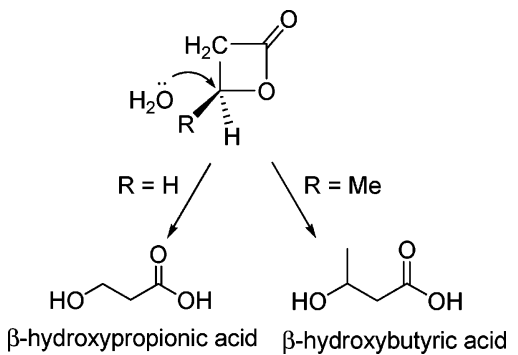

\section{Scheme 2. Method of Monitoring the Alkylation} Reactions

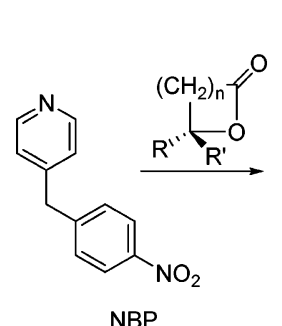

NBP

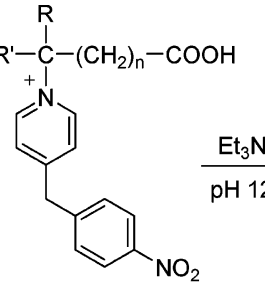

I. Colorless adduct

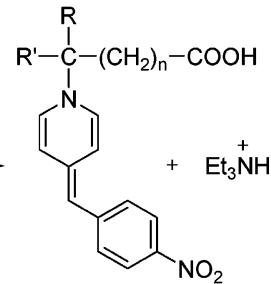

II. Blue color adduct triethylamine reagent $\left(\mathrm{Et}_{3} \mathrm{~N}\right)$ to stop the alkylation process (Scheme 2), measuring absorbance at the wavelength of maximum absorption. To render NBP soluble, the lactone + NBP alkylation mixtures were prepared in 7:3 (vol) water/dioxane medium. Detailed reaction conditions are given in the figure and table legends.

A Shimadzu UV-2101-PC spectrophotometer with a thermoelectric six cell holder temperature control system $\left( \pm 0.1^{\circ} \mathrm{C}\right)$ was used. The reaction temperature was kept constant $\left( \pm 0.05{ }^{\circ} \mathrm{C}\right)$ with a Lauda Ecoline RE120 thermostat. All kinetic runs were performed in triplicate.

BPL, BBL, and GBL were obtained from Sigma, while DVL was a Fluka product. NBP was from Sigma; $99 \% \mathrm{Et}_{3} \mathrm{~N}$ was obtained from Aldrich, and dioxane was purchased from Panreac.

Numerical treatment of the data was performed using the 7.1.44 Data Fit software. Geometry optimization of the NBPlactone adducts was carried out with the Chem3D Ultra Molecular Modeling and Analysis software, version 8.0.

\section{Results and Discussion}

Hydrolysis Reactions. We investigated the hydrolysis of BPL, BBL, GBL, and DVL in 7:3 (vol) water/dioxane medium (Scheme 1). No hydrolysis of GBL or DVL was observed. This result is consistent with our previous results reporting that these two lactones require acid media for their hydrolysis to occur (8).

Regarding BPL and BBL, experiments performed to determine the influence of the lactone concentration revealed the reactions to be first-order with respect to this reagent:

$$
\frac{\mathrm{d}[\mathrm{HA}]}{\mathrm{d} t}=k\left[\mathrm{H}_{2} \mathrm{O}\right][\mathrm{L}]=k_{1}[\mathrm{~L}]
$$

where $[\mathrm{L}]$ represents the concentration of lactone, [HA] represents the concentration of the hydroxy acid formed, and $k_{1}=k\left[\mathrm{H}_{2} \mathrm{O}\right]$ is the pseudo-first-order rate constant (in the working reaction medium $\left[\mathrm{H}_{2} \mathrm{O}\right]=38.9 \mathrm{M}$ was used).

Figure 2 shows the integrated form of eq 1 in terms of the concentration of lactone at time $t,\left([\mathrm{~L}]_{t}\right)$, and its initial concentration $\left([\mathrm{L}]_{0}\right)$.

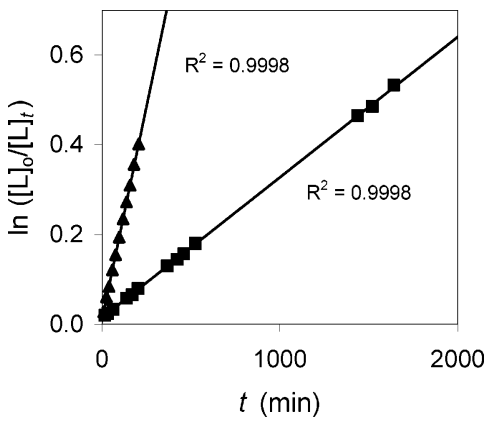

Figure 2. Integrated form of the pseudo-first-order rate equation (eq 1) for the hydrolysis of BPL ( $\mathbf{\Delta})$ and BBL ( $\mathbf{\square})$ in $7: 3$ water/dioxane medium. $[\mathrm{L}]_{0}=0.08 \mathrm{M} ; T=25{ }^{\circ} \mathrm{C}$.

Table 1. Hydrolysis Rate Constants as a Function of Temperature for BPL and BBL in 7:3 Water/Dioxane Medium $^{a}$

\begin{tabular}{ccc}
\hline & \multicolumn{2}{c}{$\mathrm{M}^{-1} \min ^{-1 b}$} \\
\cline { 2 - 3 }$T\left({ }^{\circ} \mathrm{C}\right)$ & $10^{5} \times k(\mathrm{BPL})^{c}$ & $10^{5} \times k(\mathrm{BBL})^{c}$ \\
\hline 17.5 & $2.17 \pm 0.06$ & \\
20.0 & $2.97 \pm 0.05$ & \\
22.5 & $3.85 \pm 0.06$ & $0.594 \pm 0.002$ \\
25.0 & $4.88 \pm 0.05$ & $0.806 \pm 0.007$ \\
27.5 & $6.64 \pm 0.04$ & $1.08 \pm 0.01$ \\
30.0 & $8.7 \pm 0.1$ & $1.385 \pm 0.007$ \\
32.5 & $11.4 \pm 0.4$ & $1.86 \pm 0.02$ \\
35.0 & $15.2 \pm 0.4$ & $2.47 \pm 0.02$
\end{tabular}

${ }^{a}[\mathrm{BPL}]_{0}=[\mathrm{BBL}]_{0}=0.08 \mathrm{M} .{ }^{b}$ Values of rate constants are given within the $95 \%$ confidence interval. ${ }^{c}$ As $k$ in eq 1 .

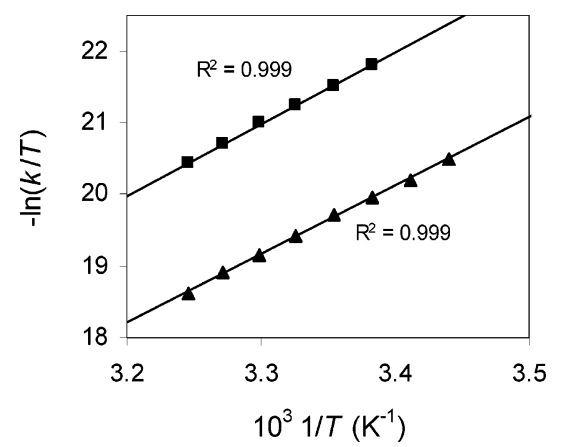

Figure 3. Eyring plots for the hydrolysis of BPL (A) and BBL $(\boldsymbol{\square})$ in $7: 3$ water/dioxane medium. $[\mathrm{BPL}]_{0}=0.08 \mathrm{M} ;[\mathrm{BBL}]_{0}=$ $0.08 \mathrm{M}$.

Table 2. Activation Parameters for the Hydrolysis of BPL and BBL in 7:3 Water/Dioxane Medium

\begin{tabular}{cccc}
\hline lactone & $\begin{array}{c}\Delta H^{\# a} \\
\left(\mathrm{~kJ} \mathrm{~mol}^{-1}\right)\end{array}$ & $\begin{array}{c}-\Delta S^{\# a} \\
\left(\mathrm{~J} \mathrm{~K}^{-1} \mathrm{~mol}^{-1}\right)\end{array}$ & $\begin{array}{c}\Delta G^{\# a}\left(35^{\circ} \mathrm{C}\right) \\
\left(\mathrm{kJ} \mathrm{mol}^{-1}\right)\end{array}$ \\
\hline BPL & $79 \pm 1$ & $95 \pm 3$ & $108 \pm 1$ \\
BBL & $83 \pm 1$ & $98 \pm 3$ & $113 \pm 1$
\end{tabular}

${ }^{a}$ Values are given with their standard deviations.

Table 1 gives the values of $k$ (BPL) and $k$ (BBL) (as $k$ in eq 1) for the hydrolysis reactions as a function of temperature $(T)$. As can be observed, the hydrolysis rate constant of BPL is about 6-fold greater than that of BBL.

Figure 3 shows the good fit of the results to the Eyring equation (11)

$$
k=\frac{\mathbf{k} T}{h} e^{\Delta S^{\sharp} / R} e^{-\Delta H^{\# / R T}}=\frac{\mathbf{k} T}{h} e^{-\Delta G^{\#} / R T}
$$

Table 2 shows the values obtained for the activation parameters.

Alkylation Reactions. No alkylation by either GBL or DVL was observed after 2 weeks. This lack of re- 


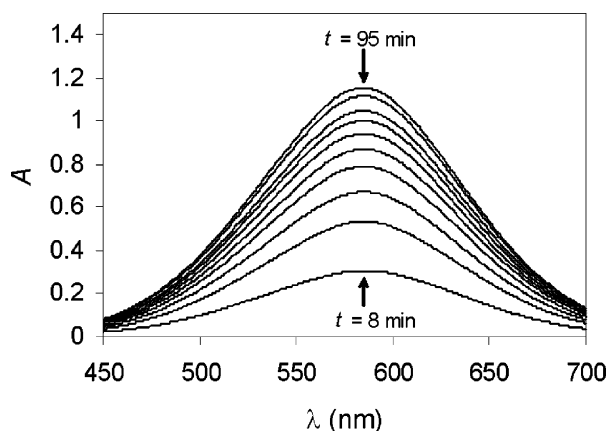

Figure 4. Spectrograms showing the formation of the NBPBPL adduct along the time in 7:3 water/dioxane medium. Variation in absorbance in the 8-95 min interval. $[\mathrm{BPL}]_{0}=4.3$ $\times 10^{-2} \mathrm{M} ;[\mathrm{NBP}]_{0}=2 \times 10^{-4} \mathrm{M} ; T=35^{\circ} \mathrm{C}$.

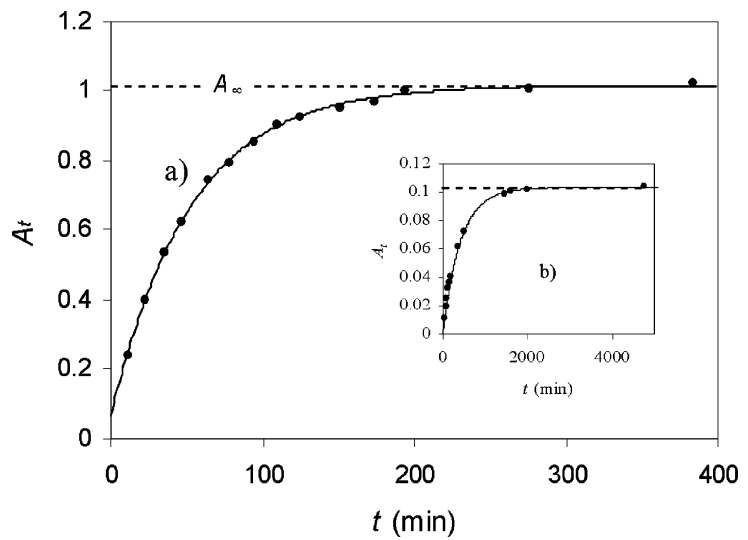

Figure 5. Formation of the NBP-BPL adduct (a) and NBPBBL adduct (b) in 7:3 water/dioxane medium. Variation in absorbance with time, $A_{\infty}$ being the absorbance of the adducts when all of the NBP has been consumed. $[\mathrm{NBP}]_{0}=2 \times 10^{-4} \mathrm{M}$; $[\mathrm{BPL}]_{0}=4.3 \times 10^{-2} \mathrm{M} ;[\mathrm{BBL}]_{0}=4.9 \times 10^{-2} \mathrm{M} ; T=27.5^{\circ} \mathrm{C}$.

\section{Scheme 3. Concurrent Hydrolysis and Alkylation}

$$
\begin{aligned}
& \text { Reactions } \\
& \left([\mathrm{L}]_{0}-x-y\right)\left\{\begin{array}{l}
+\mathrm{H}_{2} \mathrm{O} \\
{\left[\mathrm{H}_{2} \mathrm{O}\right]-y \approx\left[\mathrm{H}_{2} \mathrm{O}\right] \stackrel{k_{1}}{\longrightarrow} y} \\
+\mathrm{NBP} \\
{[\mathrm{NBP}]_{0}-x \stackrel{k_{\text {alk }}}{\longrightarrow} \mathrm{AD} \equiv x}
\end{array}\right\}
\end{aligned}
$$

activity is in agreement with their loss of ring strain (Figure 1).

The blue-colored adducts NBP-BPL and NBP-BBL showed maximum absorption at $\lambda=584 \mathrm{~nm}$ and $\lambda=586$ $\mathrm{nm}$, respectively. As an example, Figure 4 shows the increase in absorption caused by the formation of the $\mathrm{NBP}-\mathrm{BPL}$ adduct along time, until no change in absorbance $A$ was observed (because lactone was in large excess, it may be assumed that all the NBP was consumed).

Figure 5 represents typical kinetic runs for the alkylation of NBP by BPL and BBL. As can be observed, the $A_{t}$ values ( $y$-axis) in the case of the NBP-BPL adduct are about 10 -fold greater than for the NBP-BBL adduct. This must be due to the different values of the respective absorption coefficients (see below).

By designating the fraction of lactone converted into adduct $(\mathrm{AD})$ in the alkylation reaction as $x$ and that disappeared in the hydrolysis reaction as $y$ (Scheme 3),

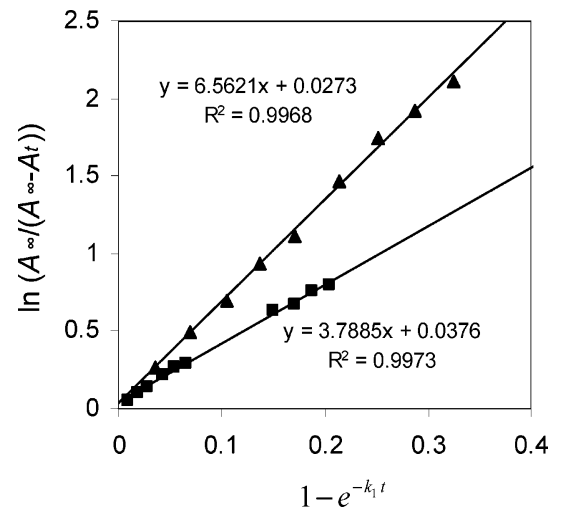

Figure 6. Determination of the alkylation rate constants (as $k_{\text {alk }}$ in eq 2) for BPL (A) and BBL ( $)$ in 7:3 water/dioxane medium. $[\mathrm{BPL}]_{0}=0.036 \mathrm{M} ;[\mathrm{BBL}]_{0}=0.037 \mathrm{M} ;[\mathrm{NBP}]_{0}=2 \times$ $10^{-4} \mathrm{M} ; T=30^{\circ} \mathrm{C}$.

Table 3. Alkylation Rate Constants as a Function of Temperature for BPL and BBL in 7:3 Water/Dioxane Medium

\begin{tabular}{ccc}
\hline & \multicolumn{2}{c}{$\mathrm{M}^{-1} \min ^{-1 a}$} \\
\cline { 2 - 3 }$T\left({ }^{\circ} \mathrm{C}\right)$ & $10 \times k_{\mathrm{BPL}}$ & $10 \times k_{\mathrm{BBL}}$ \\
\hline 25.0 & $4.7 \pm 0.4$ & $0.40 \pm 0.02$ \\
27.5 & $5.2 \pm 0.2$ & $0.48 \pm 0.02$ \\
30.0 & $6.2 \pm 0.4$ & $0.55 \pm 0.02$ \\
32.5 & $7.1 \pm 0.4$ & $0.64 \pm 0.03$ \\
35.0 & $8.2 \pm 0.3$ & $0.78 \pm 0.04$
\end{tabular}

${ }^{a}$ Values of rate constants (as $k_{\text {alk }}$ in eq 2) are given within the $95 \%$ confidence interval.

one has eqs 2 and 3 (12).

$$
\begin{gathered}
\frac{\mathrm{d} x}{\mathrm{~d} t}=\frac{\mathrm{d}[\mathrm{AD}]}{\mathrm{d} t}=k_{\mathrm{alk}}\left([\mathrm{NBP}]_{\mathrm{o}}-x\right)\left([\mathrm{L}]_{\mathrm{o}}-x-y\right) \\
\frac{\mathrm{d} y}{\mathrm{~d} t}=k_{1}\left([\mathrm{~L}]_{\mathrm{o}}-x-y\right)
\end{gathered}
$$

The combination of eqs 2 and 3 yields

$$
\begin{aligned}
\frac{\mathrm{d}[\mathrm{AD}]}{\mathrm{dt}}=k_{\mathrm{alk}}\left([\mathrm{NBP}]_{\mathrm{o}}-[\mathrm{AD}]\right)\left([\mathrm{L}]_{\mathrm{o}}-[\mathrm{AD}]\right)- \\
k_{1}\left([\mathrm{NBP}]_{\mathrm{o}}-[\mathrm{AD}]\right) \ln \frac{[\mathrm{NBP}]_{\mathrm{o}}}{[\mathrm{NBP}]_{\mathrm{o}}-[\mathrm{AD}]}
\end{aligned}
$$

Integration of eq 4 and substitution of [AD] by the absorbance, $A=[\mathrm{AD}] / \epsilon, \epsilon$ being the molar absorption coefficient of the adducts, yields eq 5

$$
\ln \frac{A_{\infty}}{A_{\infty}-A_{t}}=\frac{k_{\mathrm{alk}}[\mathrm{L}]_{\mathrm{o}}}{k_{1}}\left(1-e^{-k_{1} t}\right)
$$

where $A_{\infty}$ is the absorbance of the adducts when the plateau is reached (Figure 5).

Because the $k_{1}$ values were measured in the first part of this work, plotting $\ln \left[A_{\infty} /\left(A_{\infty}-A_{t}\right)\right]$ values against those of $\left(1-e^{-k_{1} t}\right)$ should give a straight line, from whose slope it is possible to calculate the value of $k_{\text {alk. }}$. Figure 6 shows the excellent fit of the results to eq 5 , with the intercept not significantly different from zero. Table 3 shows the $k_{\text {alk }}$ values obtained at different temperatures.

The results in Table 3 show that the alkylating potential (expressed as the alkylating rate constant $k_{\text {alk }}$ ) of BPL is about 10-fold higher than that of BBL. 


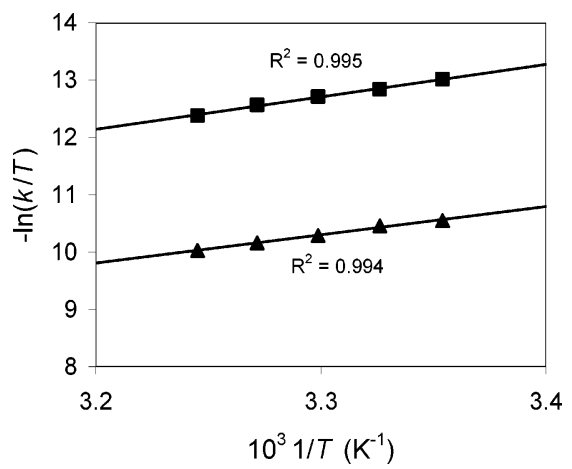

Figure 7. Eyring plots for NBP alkylation reactions by BPL (A) and BBL (ם) in 7:3 water/dioxane medium.

Table 4. Activation Parameters for NBP Alkylation by BPL and BBL in 7:3 Water/Dioxane Medium

\begin{tabular}{cccc}
\hline lactone & $\begin{array}{c}\Delta H^{\# a} \\
\left(\mathrm{~kJ} \mathrm{~mol}^{-1}\right)\end{array}$ & $\begin{array}{c}-\Delta S^{\# a} \\
\left(\mathrm{~J} \mathrm{~K}^{-1} \mathrm{~mol}^{-1}\right)\end{array}$ & $\begin{array}{c}\Delta G^{\# a}\left(35^{\circ} \mathrm{C}\right) \\
\left(\mathrm{kJ} \mathrm{mol}^{-1}\right)\end{array}$ \\
\hline BPL & $41 \pm 2$ & $148 \pm 6$ & $87 \pm 2$ \\
BBL & $47 \pm 2$ & $148 \pm 6$ & $93 \pm 2$
\end{tabular}

${ }^{a}$ Values are given with their standard deviations.

Figure 7 shows the good fit of the alkylation rate constants to the Eyring equation. Table 4 shows the values of the activation parameters.

The values of the activation parameters shown in Table 4 , as well as those reported in Table 2 referring to the hydrolysis reactions, clearly demonstrate that the reactivity of these lactones is essentially enthalpy-controlled. The higher $\Delta H^{\#}$ value obtained for alkylation by BBL must be caused, as in the case of its hydrolysis, by the methyl group as a donor of charge on the $\beta$-carbon, with a decrease in its electrophilic character (Scheme 1). Nevertheless, it should be noted that since, in general, substitution on carbon atoms -2 or -3 in lactones weakens their carcinogenic activity $(4,13)$, the steric hindrance of the BBL methyl group must also contribute to the higher value of $\Delta H^{\#}$. The same $\Delta S^{\#}$ values found for both lactones (Table 4) are consistent with their analogous geometry.

Because BPL and BBL are possibly carcinogenic for humans $(4,5)$, we wondered about the effect of their transformation into the respective hydroxy acids by hydrolysis on their effectiveness as alkylating agents. Figure 8 shows the comparative yields of hydrolysis and alkylation reactions over time.

These results allow one to assume that in the formation of lactones by nitrosation of primary amino acids (1-3), the transformation of lactones into the corresponding hydroxy acid is not sufficiently effective to prevent alkylation [it should be noted that since hydrolysis of BPL and BBL occurs through alkyl cleavage, the hydrolysis rate constants are practically invariable in the $0<\mathrm{pH}$ $<9$ range $(14-16)]$.

The kinetic results obtained are consistent with the biological activity of these lactones (Table 5): sufficient evidence in experimental animals for the carcinogenicity of BPL and BBL and evidence suggesting a lack of carcinogenicity for GBL (5). The results also suggest that the NBP test is a simple and reliable primary assay for the evaluation of carcinogenic potential.

A kinetic study of alkylation and competing hydrolysis by BPL and BBL was also performed at several water/ dioxane ratios. Table 6 shows the results.
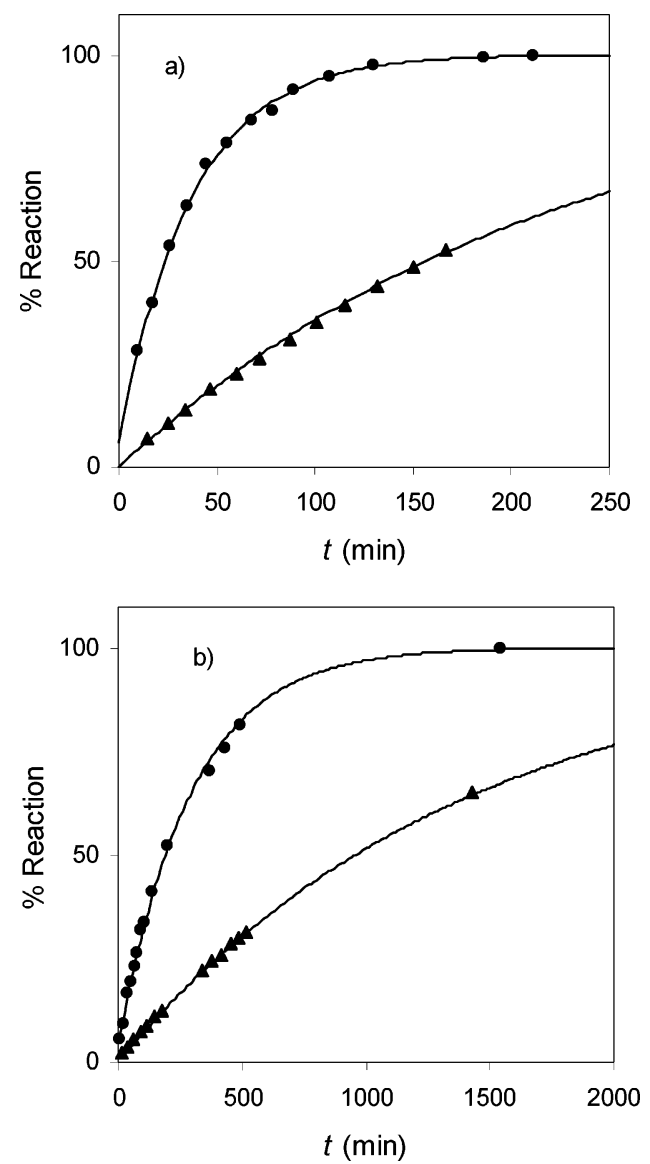

Figure 8. Hydrolysis of lactones ( $\Delta$ ) and NBP alkylation reactions ( $\square$ ) for (a) BPL and (b) BBL in 7:3 water/dioxane medium. Hydrolysis: $[\mathrm{BPL}]_{\mathrm{o}}=[\mathrm{BBL}]_{\mathrm{o}}=0.08 \mathrm{M} ; T=32.5{ }^{\circ} \mathrm{C}$; $\%$ reaction $=100 \times[\mathrm{L}]_{t} /[\mathrm{L}]_{0}$. Alkylation: $[\mathrm{BPL}]_{0}=4.3 \times 10^{-2} \mathrm{M}$; $[\mathrm{BBL}]_{\mathrm{o}}=6.2 \times 10^{-2} \mathrm{M} ;[\mathrm{NBP}]_{\mathrm{o}}=2 \times 10^{-4} \mathrm{M} ; T=32.5{ }^{\circ} \mathrm{C}$; $\%$ reaction $=100 \times[\mathrm{NBP}]_{t} /[\mathrm{NBP}]_{0}$.

As may be seen, the efficiency of alkylation expressed as the alkylation rate/hydrolysis rate ratio $\left(k_{\text {alk }} / k\right)$ clearly decreases when the amount of dioxane in the reaction medium increases. A possible explanation for this is that the organic solvent molecules would stabilize the lactones' ground state more than water, resulting in lower activities of BPL and BBL as alkylating agents.

This result may be useful when working with hydrophilic/lipophilic media, such as in food science. For instance, the results may be significant in cases of the presence in the human stomach of mixtures of alcoholic spirits and food containing vegetable oils, such as salads, or food coming from the preserves industry. When the water/organic component ratio decreases, a slowing down of the efficiency of the alkylation reactions would be expected.

Molar Absorption Coefficients of NBP-Lactone Adducts. We were also interested in knowing the molar absorption coefficients of the NBP-BPL and NBP-BBL adducts. Knowledge of these values should permit easy determination of the concentration of the adducts by simply measuring the absorbance.

Five experiments were performed using $[\mathrm{NBP}]=2 \times$ $10^{-4} \mathrm{M}$ and lactone concentrations in the $0.01-0.04 \mathrm{M}$ range for BPL and 0.01-0.06 $\mathrm{M}$ for BBL. When absorbance reached a plateau (see Figure 5), we assumed that the reaction of NBP with the alkylating agent had reached $100 \%$. The mean values obtained at $32.5{ }^{\circ} \mathrm{C}$ were 
Table 5. Alkylating Potential of BPL and BBL and Their Tumorigenicity/Carcinogenicity

\begin{tabular}{|c|c|c|c|c|c|}
\hline \multirow[b]{3}{*}{ lactone } & \multirow[b]{3}{*}{$\begin{array}{c}\text { alkylation potential } \\
(\text { this work; Table } 3) \\
10 \times k_{\mathrm{alk}^{a}}\left(\mathrm{M}^{-1} \mathrm{~min}^{-1}\right)\end{array}$} & \multicolumn{4}{|c|}{ tumorigenicity (13) } \\
\hline & & \multicolumn{2}{|c|}{ subcutaneous injection in mice ${ }^{b}$} & \multicolumn{2}{|c|}{ subcutaneous injection in rats $^{c}$} \\
\hline & & $\begin{array}{l}\text { dose } \\
(\mathrm{mg})\end{array}$ & $\begin{array}{l}\text { no. of malignant } \\
\text { tumors at injection } \\
\text { site/no. of animals }\end{array}$ & $\begin{array}{l}\text { dose } \\
(\mathrm{mg})\end{array}$ & $\begin{array}{l}\text { no. of malignant } \\
\text { tumors at injection } \\
\text { site/no. of animals }\end{array}$ \\
\hline BPL & $8.2 \pm 0.3$ & 0.73 & $18 / 30$ & 4 & $13 / 20$ \\
\hline BBL & $0.78 \pm 0.04$ & 10 & $18 / 30$ & 100 & $9 / 20$ \\
\hline GBL & no reaction & \multirow{2}{*}{\multicolumn{4}{|c|}{$\begin{array}{l}\text { not classifiable as to its carcinogenicity to humans (group 3) (5) } \\
\text { no data on carcinogenicity available }\end{array}$}} \\
\hline DVL & no reaction & & & & \\
\hline
\end{tabular}

Table 6. Relative Efficiency of Alkylation by Lactones When Compared to Their Hydrolysis at Different Water/ Dioxane Ratios $^{a}$

\begin{tabular}{cccccc}
\hline & \multicolumn{2}{c}{$\mathrm{BPL}$} & & \multicolumn{2}{c}{$\mathrm{BBL}$} \\
\cline { 2 - 3 } \cline { 5 - 6 } $\begin{array}{c}\text { water/dioxane } \\
\text { (vol. ratio) }\end{array}$ & $\begin{array}{c}10 \times k_{\mathrm{alk}}^{b} \\
\left(\mathrm{M}^{-1} \mathrm{~min}^{-1}\right)^{d}\end{array}$ & $k_{\text {alk }}{ }^{b} / k^{c}$ & & $\begin{array}{c}10 \times k_{\text {alk }}^{b} \\
\left(\mathrm{M}^{-1} \mathrm{~min}^{-1}\right)^{d}\end{array}$ & $k_{\text {alk }}{ }^{b} / k^{c}$ \\
\hline $7 / 3$ & $5.2 \pm 0.2$ & 7843 & & $0.48 \pm 0.02$ & 4444 \\
$6 / 4$ & $3.9 \pm 0.2$ & $7677^{e}$ & & $0.17 \pm 0.01$ & $2396^{e}$ \\
$5 / 5$ & $3.0 \pm 0.1$ & $7126^{e}$ & & $0.08 \pm 0.01$ & $1765^{e}$ \\
$4 / 6$ & $1.6 \pm 0.1$ & $5926^{e}$ & & $0.03 \pm 0.01$ & $967^{e}$ \\
$2 / 8$ & $0.150 \pm 0.003$ & 1500 & & $0.0060 \pm 0.0004$ & 735
\end{tabular}

${ }^{a}[\mathrm{BPL}]_{\mathrm{o}}=4.3 \times 10^{-2} \mathrm{M} ;[\mathrm{BBL}]_{\mathrm{o}}=6.2 \times 10^{-2} \mathrm{M} ; T=27.5^{\circ} \mathrm{C}$. ${ }^{b}$ As $k_{\text {alk }}$ in eq 2. ${ }^{c}$ As $k$ in eq $1 .{ }^{d}$ Values of rate constants are given within the $95 \%$ confidence interval. ${ }^{e}$ Values from ref 8 .
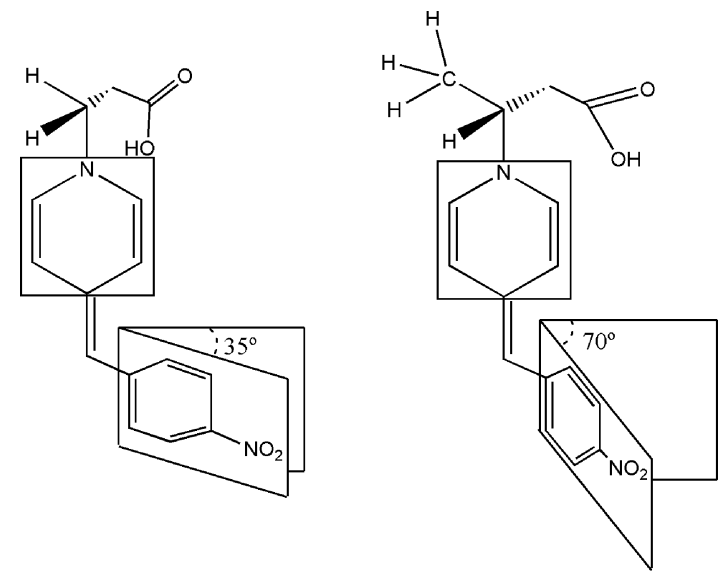

Figure 9. Lack of coplanarity in the NBP-BPL and NBPBBL adducts.

$\epsilon_{\mathrm{NBP}-\mathrm{BPL}}=5101 \pm 111 \mathrm{M}^{-1} \mathrm{~cm}^{-1}(\lambda=584 \mathrm{~nm})$ and $\epsilon_{\mathrm{NBP}-\mathrm{BBL}}=462 \pm 19 \mathrm{M}^{-1} \mathrm{~cm}^{-1}(\lambda=586 \mathrm{~nm})$.

As may be seen, the absorption coefficient of the NBPBPL adduct is 11-fold greater than that of NBP-BBL. To rationalize this result, the structures of both adducts were obtained by a geometry optimization. This analysis revealed the existence of a different lack of coplanarity of the two NBP-phenyl rings (Figure 9). While in the case of the BPL adduct the dihedral angle was about $35^{\circ}$, in the $\mathrm{NBP}-\mathrm{BBL}$ adduct, the torsion angle was estimated to be $70^{\circ}$. The more intense lack of coplanarity in the $\mathrm{NBP}-\mathrm{BBL}$ adduct disrupting the $\pi$-electron cloud to interlink the two phenyl rings would lead to a smaller $\epsilon$ value, as was observed.

To gain information about the values of the molar absorption coefficients in media of different compositions, measurements were made working with several water/ dioxane ratios. Figure 10 shows the results. It should be noted that increasing the water concentration caused a bathochromic effect in the visible spectra of the adducts,

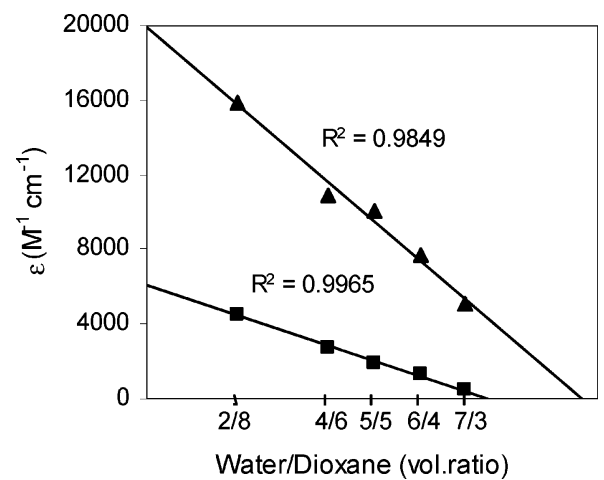

Figure 10. Variation in the molar absorption coefficients of the adducts in different water/dioxane media. NBP-BPL ( $\mathbf{\Delta}$; $\mathrm{NBP}-\mathrm{BBL}(\mathbf{\square}) .[\mathrm{BPL}]_{0}=4.3 \times 10^{-2} \mathrm{M} ;[\mathrm{BBL}]_{0}=6.2 \times 10^{-2} \mathrm{M}$; $[\mathrm{NBP}]_{\mathrm{o}}=2 \times 10^{-4} \mathrm{M} ; T=27.5^{\circ} \mathrm{C}$.

as generally occurs for $\pi \rightarrow \pi^{*}$ transitions in aromatic chromophores (17).

\section{Conclusions}

(i) GBL and DVL afford neither appreciable NBP alkylation nor hydrolysis reactions; (ii) the alkylating potential of BPL is 10 -fold higher than that of $\mathrm{BBL}$, and the reactivities of both are essentially enthalpy-controlled; (iii) a correlation was found between the alkylating potential of lactones and their carcinogenicity; (iv) the hydrolysis of lactones is not sufficiently effective to prevent alkylation; (v) the efficiency of alkylation, expressed as the alkylation rate/hydrolysis rate ratio, decreases strongly with increasing amounts of dioxane in the reaction medium; (vi) the absorption coefficients of the NBP-lactone adducts are $\epsilon_{\mathrm{NBP}-\mathrm{BPL}}=5101 \pm 111$ $\mathrm{M}^{-1} \mathrm{~cm}^{-1}(\lambda=584 \mathrm{~nm})$ and $\epsilon_{\mathrm{NBP}-\mathrm{BBL}}=462 \pm 19 \mathrm{M}^{-1} \mathrm{~cm}^{-1}$ $(\lambda=586 \mathrm{~nm})$, the pronounced difference between these values being rationalized in terms of the adducts' structure; and (vii) linear correlations exist between the adducts' absorption coefficients and the water/dioxane ratio in the reaction medium.

Acknowledgment. We thank the Spanish Ministerios de Ciencia y Tecnología (Project BQU2001-1934) and Educación y Ciencia (Project CTQ2004-05048/BQU), as well as the Spanish Junta de Castilla y León (Grant SA003/02) for supporting the research reported in this article. M.T.P.P. and J.A.M. also thank the Ministerio de Ciencia y Tecnología and the Junta de Castilla y León for Ph.D. grants. Thanks are also given for the valuable comments made by the referees.

\section{References}

(1) García Santos, M. P., Calle, E., and Casado, J. (2001) Amino acid nitrosation products as alkylating agents. J. Am. Chem. Soc. 123 $7506-7510$. 
(2) García Santos, M. P., González Mancebo, S., Hernández Benito, J., Calle, E., and Casado, J. (2002) Reactivity of amino acids in nitrosation reactions and its relation to the alkylating potential of their products. J. Am. Chem. Soc. 124, 2177-2182.

(3) García Santos, M. P., Calle, E., and Casado, J. (2003) A method for the kinetic study of amino acid nitrosation reactions. Polyhedron 22, 1059-1066.

(4) Lawley, P. D. (1984) Carcinogenesis by alkylating agents. In Chemical Carcinogens, 2nd ed. (Searle, C. E., Ed.) Chapter 7, ACS Monograph 182, American Chemical Society, Washington, DC.

(5) IARC (1999) Reevaluation of Some Organic Chemicals, Hydrazine and Hydrogen Peroxide, pp 367, 1103, and 1317, IARC Monograph 71, IARC, Lyon, France.

(6) Kim, J. H., and Thomas, J. J. (1992) Use of 4-(4-nitrobenzyl)pyridine (4-NBP) to test mutagenic potential of slow-reacting epoxides, their corresponding olefins, and other alkylating agents. Bull. Environ. Contam. Toxicol. 49, 879-885.

(7) Shephard, S. E., and Lutz, W. K. (1989) Nitrosation of dietary precursors. Cancer Surv. 8, 401-421.

(8) Pérez Prior, M. T., Manso, J. A., García Santos, M. P., Calle, E., and Casado, J. (2005) Reactivity of lactones and GHB formation. J. Org. Chem. 70, 420-426.

(9) Shephard, S. E., Hegi, M., and Lutz, W. K. (1987) In vitro assays to detect alkylating and mutagenic activities of dietary components nitrosated in situ. In The Relevance of $\mathrm{N}$-Nitroso Com- pounds to Human Cancer: Exposure and Mechanisms (Bartsch, H., O’Neill, I. K., and Schulte-Hermann, R., Eds.) pp 232-236, IARC Scientific Publication No. 84, IARC, Lyon, France.

(10) CRC Handbook of Chemistry and Physics, 85th ed. (2004-2005) CRC Press, Boca Ratón, FL.

(11) Connors, K. A. (1990) Chemical Kinetics, the Study of Reaction Rates in Solution, Chapter 6, VCH, New York.

(12) Jungers, J. C., Sajus, L., Aguirre, I., and Decroocq, D. (1967) L'Analyse Cinétique de la Transformation Chimique, Chapter 3, Technip, Paris.

(13) Van Duuren, B. L. (1969) Carcinogenic epoxides, lactones, and halo-ethers and their mode of action. Ann. N. Y. Acad. Sci. 163, 633-651.

(14) Long, F. A., and Purchase, M. (1950) The kinetics of hydrolysis of $\beta$-propiolactone in acid, neutral and basic solutions. J. Am. Chem. Soc. 72, 3267-3273.

(15) Kaiser, E. T., and Kézdy, F. J. (1976) Hydrolysis of cyclic esters. Prog. Bioorg. Chem. 4, 239-267.

(16) March, J. (1992) Advanced Organic Chemistry. Reactions, Mechanisms and Structure, 4th ed., p 381, John Wiley, New York.

(17) Rao, C. N. (1967) Ultra-Violet and Visible Spectroscopy, Chapter 2, Butterworth, London.

TX050031D 